\title{
Dissimilar Welding of Al and Mg Alloys by FSW
}

\author{
Taiki Morishige ${ }^{1, * 1}$, Atsushi Kawaguchi ${ }^{1, * 2}$, Masato Tsujikawa ${ }^{1}$, \\ Makoto Hino ${ }^{2}$, Tomotake Hirata ${ }^{3}$ and Kenji Higashi ${ }^{1}$ \\ ${ }^{1}$ Department of Materials Science, Osaka Prefecture University, Sakai 599-8531, Japan \\ ${ }^{2}$ Industrial Technology Research Institute of Okayama Prefecture, Okayama 701-1296, Japan \\ ${ }^{3}$ Technology Research Institute of Osaka Prefecture, Izumi 594-1157, Japan
}

\begin{abstract}
Microstructures and mechanical properties of dissimilar welding joint between $\mathrm{Al}$ alloy and $\mathrm{Mg}$ alloy by Friction Stir Welding (FSW) were investigated in comparison with laser welding of the same combination. Dissimilar joint of $\mathrm{Al}$ and $\mathrm{Mg}$ alloy by laser welding was very brittle because of building up $\mathrm{Mg}_{17} \mathrm{Al}_{12}$ inter metallic compounds in fusion zone. On the other hand, $\mathrm{FSW}$ is anticipated to welding dissimilar alloys with enough joint strength because it is a solid-state process without melting. In this paper, FSW was carried out to make dissimilar butt joints of $\mathrm{Al}$ alloy and AZ31 magnesium alloy with various tool rotational speed and welding speed. These joints showed higher hardness in their stir zones than that of parent AZ31 alloy because of Mg-Al inter metallic compound formation. However, the hardness of stir zone was lower than that of fusion zone of laser welding, and was changed with the welding parameters of tool rotational speed and welding speed (i.e. heat input ratio of FSW). The optimum welding conditions of $\mathrm{Mg}$ and $\mathrm{Al}$ dissimilar FSW joint and the influence of inter metallic compound distribution with mixing of materials in stir zone were discussed. [doi:10.2320/matertrans.MC200768]
\end{abstract}

(Received October 19, 2007; Accepted November 26, 2007; Published January 17, 2008)

Keywords: friction stir welding (FSW), dissimilar welding, A5052, AZ31, heat input ratio

\section{Introduction}

Friction Stir Welding (FSW) ${ }^{1,2)}$ is a solid state welding method developed by The Welding Institute (TWI) in UK. Thermal heating and mechanical stirring originated by the rotational tool with probe join two pieces of alloy plates. For light metal alloys, welding by FSW is expected in transport industries due to the high quality of the joint because of the low temperature processing without melting. It is considered by many to be the most significant development in metal joining in a decade.

Commercial magnesium alloys do not have enough strength to apply for structural materials. However, magnesium alloys are attractive to reduce the weight products. On the other hand, aluminum alloys have been used for products required high strength. Magnesium alloy and aluminum alloy should be used in the proper portion of the part of structure. The joint of these dissimilar metals required. However, dissimilar welding between aluminum alloy and magnesium alloy by conventional fusion welding ${ }^{3,4)}$ is unable because of the vast volume of $\mathrm{Mg}_{17} \mathrm{Al}_{12}$ intermetallic compound formation in the fusion zone. The processing temperature during FSW does not reach melting points of the alloys, so the formation of intermetallic compounds in stir zone is limited. ${ }^{5-7)}$ These intermetallic compounds should be dispersed finely to prevent the brittleness. ${ }^{9,10)}$

In this paper, dissimilar FSW joint between non-heattreating type A5052-H aluminum alloy and extruded AZ31B magnesium alloys were produced. The heat input ratio and the formation of intermetallic compounds in stir zone was reduced as much as possible. In addition, the influence on welding parameters on joint characteristic was discussed.

\footnotetext{
${ }^{* 1}$ Graduate Student, Osaka Prefecture University

*2Undergraduate Student, Osaka Prefecture University
}

\section{Experimental Procedures}

The materials used for butt joints were extruded AZ31B magnesium alloy and A5052-H aluminum alloy plate. The plate thickness was nominally $3[\mathrm{~mm}]$. These materials were put on the table of high-powered FSW machine that the tool advancing side was $\mathrm{Al}$ plate and retreating side was $\mathrm{Mg}$ plate. The rotational tool was inserted along the center of butt line.

The material of FSW tool was JIS SKD61 tool steel. The tool has shoulder with 12 [mm] in diameter, and has probe with $4[\mathrm{~mm}]$ in diameter and $2.9[\mathrm{~mm}]$ in length. The inclination angle used was $3^{\circ}$ degree. Tool load was $10[\mathrm{kN}]$. The FSW conditions - tool rotational speed, $R_{t}$, and welding speed, $V$-were changed from 800 to $1600\left[\mathrm{~min}^{-1}\right]$ and from 100 to $400[\mathrm{~mm} / \mathrm{min}]$, respectively. Welded joint samples were estimated in cross-sectional to the welding direction by microstructural observation (optical microscopy and fieldemission scanning microscopy).

Micro-Vickers hardness measurements were made along the cross-section of the weld. The load was set at 0.098 [N]. Microstructural observations were performed by optical microscope with etching (for $\mathrm{Mg}$ side, 4.2 [g] picric acid, in mixture of $70 \mathrm{~mL}$ methanol, $10 \mathrm{~mL}$ acetic acid and $10 \mathrm{~mL}$ distilled water, and for Al side, electrolytic etching). Tensile tests were carried out by dog-bone test piece that of the parallel part is $30[\mathrm{~mm}]$ and the width is $12[\mathrm{~mm}]$. The sample surface was as-welded (thickness was $3[\mathrm{~mm}]$ ) without milling of the weld surface. Base materials and dissimilar joints were performed tensile tests three samples on each welding conditions.

\section{Results}

\subsection{Welding conditions}

For A5052-H or AZ31B alloy plate, the welding conditions were searched by stir-on-plate. Each alloy could be welded at wide range conditions. On the other hand, dissimilar butt-welded samples were compared by surface 


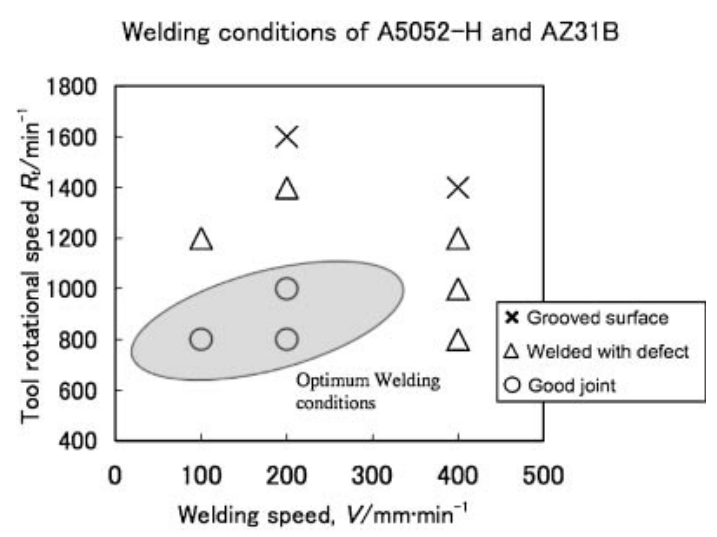

Fig. 1 Welding Conditions of A5052-H and AZ31B Dissimilar Joint.

conditions (existence of crack, grooving and etc.). During FSW, temperature of the material was increased with increasing the ratio of tool rotational speed $\left(R_{t}\right)$ to welding speed $(V)$. Surface defects like grooving or cavities were observed in the samples welded in higher heat input rate $\left(R_{t} / V\right){ }^{12-14)}$ This grooving was occurred by a tool seizure of the base materials. The proper joints were able to cut out without failure for microstructural observation and tensile testing sample. These results are shown in Fig. 1. The proper welding condition for dissimilar A5052-H and AZ31B FSW joint were more limited region than that for A5XXX or AZ31B FSW joint. ${ }^{11-18)}$

\subsection{Microstructural observation and hardness distribu- tions}

As-received A5052-H alloy had 20 30 [ $\mu \mathrm{m}]$ of the grain diameter. After FSW, the grain size was refined to c.a. 10 $[\mu \mathrm{m}]$ by dynamic recrystallization. FSW-ed A5052-H alloy has $70 \mathrm{HV}$ in base material region and $60 \mathrm{HV}$ in SZ. This is because the base alloy was $\mathrm{H}$ tempered plate and frictional heating made softening as heat treatment. On the other hand, in A5052-H and AZ31B dissimilar FSW welding, crosssectional macroscopic image of the conditions that 1000 $\left[\mathrm{min}^{-1}\right]$ of the tool rotational speed and $200[\mathrm{~mm} / \mathrm{min}]$ of the welding speed was shown in Fig. 2 and 3. Near SZ areas tended to form intermetallic compounds ( $\mathrm{Mg}_{17} \mathrm{Al}_{12}$ phase). In these region, the maximum hardness was 200 300HV. By $\mathrm{X}$-ray diffraction patterns (as shown in Fig. 4), a dissimilar FSW-ed sample has $\mathrm{Mg}_{17} \mathrm{Al}_{12}$ and $\mathrm{Mg}_{2} \mathrm{Al}_{3}$ intermetallic phase, however the intensity was lower than the laser welded sample. Hardness distributions of the cross section exhibited that the intermetallic compounds partly existed in SZ. True hardness of $\mathrm{Mg}_{17} \mathrm{Al}_{12}$ particles is higher than this results, because these particles were finely dispersed in SZ and the hardness was averaged with that of parent materials.

\subsection{Tensile tests}

Result of the tensile test was shown in Table 1. The tensile strength of base material was 244 [MPa] (A5052-H) and 241 [MPa] (AZ31B). All samples of the dissimilar FSW joint ruptured at $\mathrm{SZ}$ of Al side interface. The maximum UTS and elongation, $147[\mathrm{MPa}]$ and $3.4 \%$, was recorded by the joint welded at $1000\left[\mathrm{~min}^{-1}\right]$ and $200[\mathrm{~mm} / \mathrm{min}]$. The joint efficiency was achieved $61 \%$ of the strength of the base material (AZ31B). By fractography as shown in Fig. 5, the

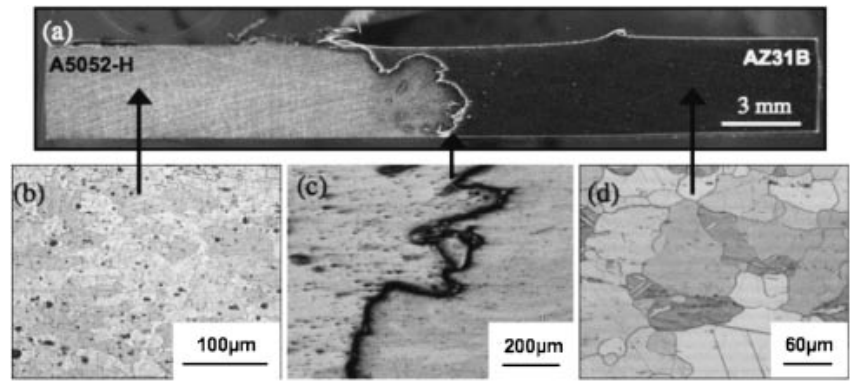

Fig. 2 Macroscopic (a) and microscopic image (b)-(d) of the cross section welded at $1000\left[\mathrm{~min}^{-1}\right]$ and $200[\mathrm{~mm} / \mathrm{min}]$.
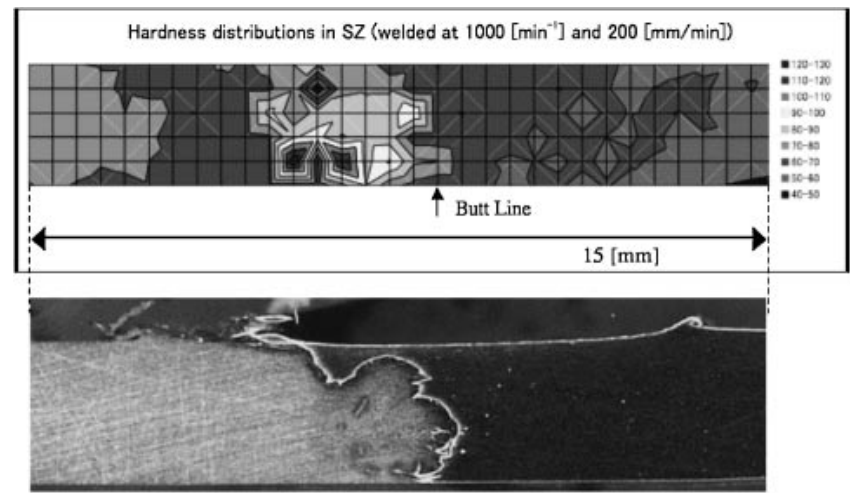

Fig. 3 Cross Sectional Hardness Distributions of the joint welded at 1000 $\left[\mathrm{min}^{-1}\right]$ and $200[\mathrm{~mm} / \mathrm{min}]$.

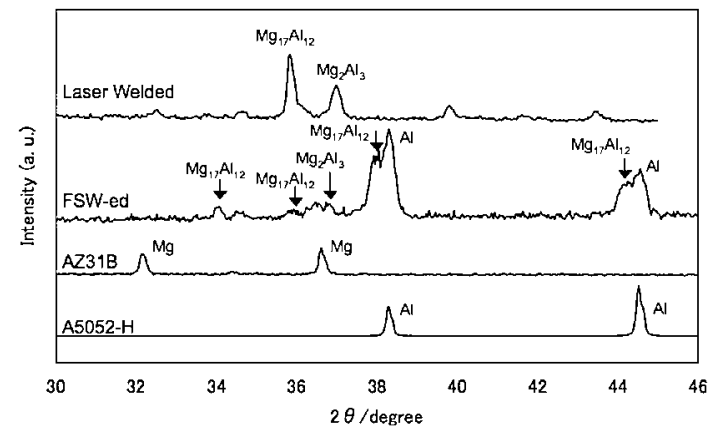

Fig. 4 X-ray diffraction patterns of base materials and dissimilar welded materials.

fracture surface in the SZ shows quite different between the upper and lower part of SZ. The upper fracture surface has cracked intermetallic phase, so this is brittle fracture. On the other hand, the lower part has dimple fracture. This ductile region caused that several percent of elongation.

\section{Discussion}

\subsection{Distributions of intermetallic compounds}

Fusion welded joints by laser were very brittle and almost no joint strength. Because almost all the fusion zone is intermetallic compounds. The maximum hardness of each welding condition in SZ was shown in Fig. 6. Except for the joint welded at $1000\left[\mathrm{~min}^{-1}\right]$ and $400[\mathrm{~mm} / \mathrm{min}]$, the maximum hardness is linear to the ratio of rotational speed to welding speed. This result means that the formation of $\mathrm{Mg}$ Al intermetallic compounds can be controlled by the heat input rate. 
Table 1 Tensile Test Result of FSW-ed Joint.

\begin{tabular}{|c|c|c|c|c|}
\hline FSW Condition & $\begin{array}{c}\text { UTS } \\
{[\mathrm{MPa}]}\end{array}$ & $\begin{array}{c}0.2 \% \text { proof } \\
\text { stress }[\mathrm{MPa}]\end{array}$ & Elongation (\%) & $\begin{array}{c}\text { Joint } \\
\text { Efficiency }(\%)\end{array}$ \\
\hline A5052-H as-received & 244 & 181 & 18.0 & - \\
\hline AZ31B as-received & 241 & 200 & 21.6 & - \\
\hline $800 \mathrm{rpm}-100 \mathrm{~mm} / \mathrm{min}$ & 115 & 69.0 & 3.4 & 48 \\
\hline $800 \mathrm{rpm}-200 \mathrm{~mm} / \mathrm{min}$ & 97 & 67.0 & 1.0 & 40 \\
\hline $1000 \mathrm{rpm}-200[\mathrm{~mm} / \mathrm{min}]$ & 147 & 64.0 & 3.4 & 61 \\
\hline
\end{tabular}
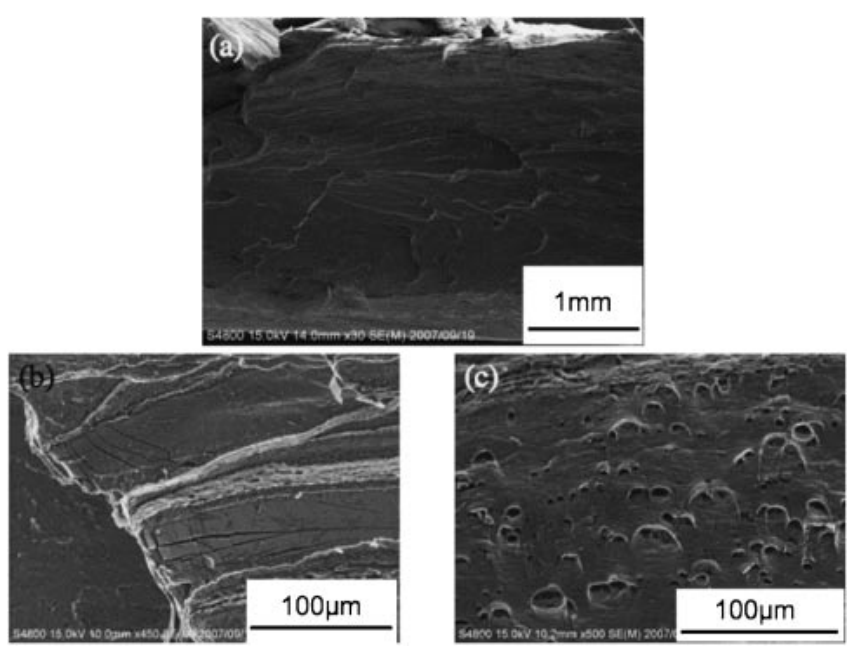

Fig. 5 Fracture surface (b) is upper part and (c) is lower part.

These intermetallic compounds mainly existed in upper part of SZ. During FSW, this Al-Mg intermetallic phase precipitate by frictional heating and mechanically stirring on interfaces of butt line. Y. S. Sato et al. ${ }^{8)}$ reported that the intermetallic compound $\mathrm{Mg}_{17} \mathrm{Al}_{12}$ was formed by constitutional liquation and solidification during FSW. In the lower part of the SZ, temperature was not enough to form the intermetallic phase.

The mechanical properties of dissimilar $\mathrm{Al}$ and $\mathrm{Mg}$ alloy plate joints depend on the distributions of Al-Mg intermetallic compounds. For improvement of the joint efficiency, it must be not only suppressed precipitates of compounds, but also finely dispersed. ${ }^{14)}$ On the other hand, less intermetallic compound phase is in FSW, and the hardness can be controlled by FSW condition. Lower the ratio of rotational speed to welding speed made less intermetallic compounds in SZ.

\section{Summary}

The dissimilar FSW joint between A5052-H aluminum alloy and AZ31B magnesium alloy was able to join and the joint efficiency was achieved to $61 \%$. This value was not enough to acquire reliable joints but much higher than that of laser welded joints. It needs to improve the distribution of the intermetallic compounds. The highest hardness of each FSW joint has the linear relation to heat input ratio. The reliable dissimilar $\mathrm{Al}$ and $\mathrm{Mg}$ FSW joint that has high joint efficiency and elongation could acquire by the lower heat input rate to suppress the formation of $\mathrm{Mg}_{17} \mathrm{Al}_{12}$ intermetallic phase.

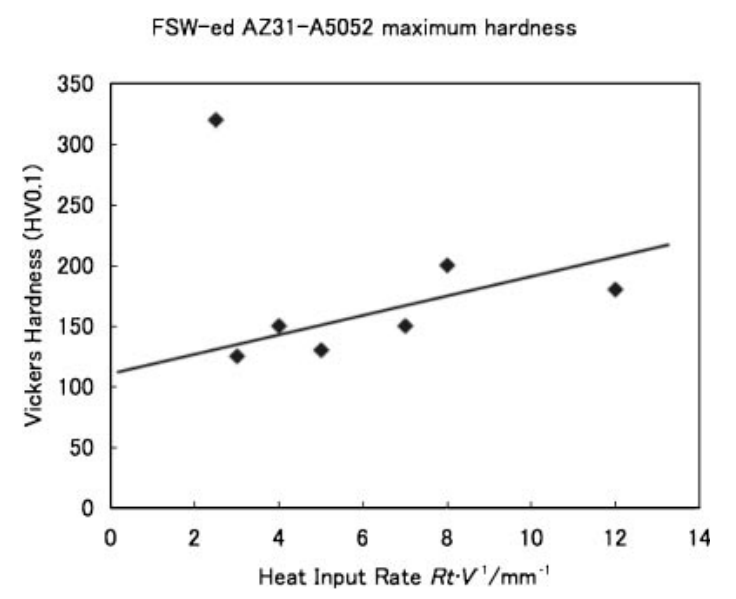

Fig. 6 Relationship between $R_{t} / V$ and maximum hardness in SZ.

\section{REFERENCES}

1) C. D. Dawes and W. M. Thomas: Weld. J. 75 (1996) 41-45.

2) R. S. Mishra and Z. Y. Ma: Mater. Sci. Eng. R 50 (2005) 1-78.

3) R. Borrisutthekul, Y. Miyashita and Y. Mutoh: Sci. Technology of Advanced Mater. 6 (2005) 199-204.

4) C. T. Chi, C. G. Chao, T. F. Liu and C. H. Lee: Scripta Mater. 56 (2007) $733-736$.

5) S. Hirano, K. Okamoto, M. Doi, H. Okamura, M. Inagaki and Y. Aono: J. Japan Welding Society 21 (2003) 539-545.

6) A. C. Somasekharan and L. E. Murr: Mater. Characterization 52 (2004) 49-64.

7) K. Savolainen, J. Mononen, T. Saukkonen and H. Hannien: Proc. 6th ISFSW, 2007.

8) Y. S. Sato, S. H. C. Park, M. Michiuchi and H. Kokawa: Scripta Mater. 50 (2004) 1233-1236.

9) S. H. C. Park, Y. S. Sato and H. Kokawa: J. Mater. Sci. 38 (2003) 43794383.

10) M. Tsujikawa, S. W. Chung, T. Morishige, L. F. Chiang, Y. Takigawa, S. Oki and K. Higashi: Mater. Trans. 48 (2007) 618-621.

11) N. Afrin, D. L. Chen, X. Cao and M. Jahazi: Mater. Sci. Eng. In press (2007).

12) K. Nakata, Y. G. Kim, M. Ushio, T. Hashimoto and S. Jyogan: ISIJ International 40 (2000), Supplement, S15-19.

13) Y. G Kim, H. Fujii, T. Tsumura, T. Komazaki and K. Nakata: Mater. Sci. Eng., A 415 (2006) 250-254.

14) H. Zhang, H. Wu, J. Huang, S. Lin and L. Wu: Rare Metals 26 (2007) 158-162.

15) M. Abbasi Gharacheh, A. H. Kokabi, G. H. Daneshi, B. Shalchi and R. Sarrafi: International J. Machine Tools and Manufacture 46 (2006) 1983-1987.

16) W. Xunhong and W. Kuaishe: Mater. Sci. Eng., A 431 (2006) 114-117.

17) Won-Bae Lee, Martin Schmuecker, Ulises Alfaro Mercardo, Gerhard Biallas and Seung-Boo Jung: Scripta Mater. 55 (2006) 355-358.

18) T. Hirata, T. Oguri, H. Hagino, T. Tanaka, S. W. Chung, Y. Takigawa and K. Higashi: Mater. Sci. Eng., A 456 (2007) 344-349.

19) A. L. Etter, T. Baudin, N. Fredj and R. Penelle: Mater. Sci. Eng., A 445 (2007) 94-99. 